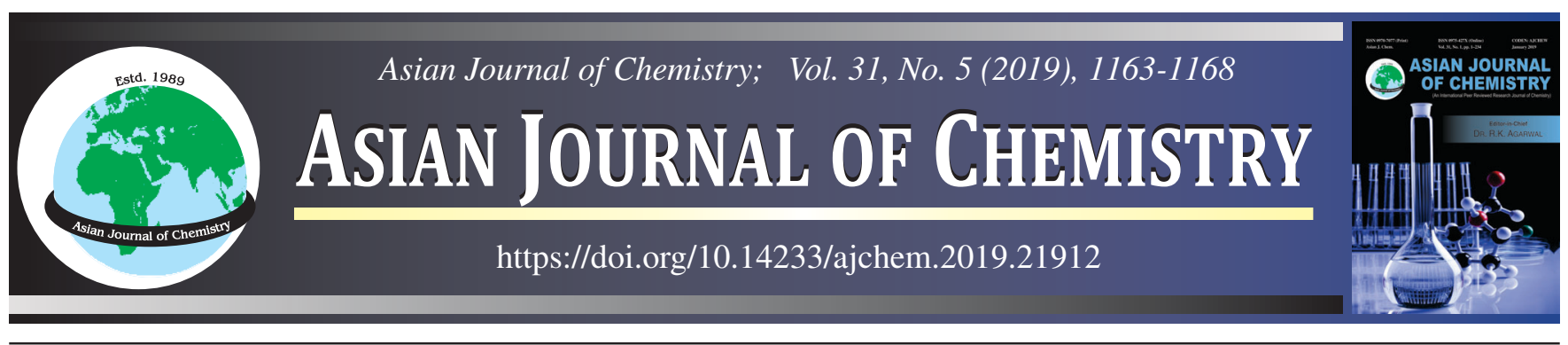

\title{
Template Assisted Synthesis of Nanoporous Carbon from Bio-Weed of Ipomoea carnea Stems for Supercapacitor Applications
}

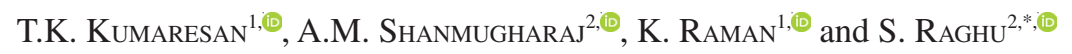

${ }^{1}$ Department of Chemistry, Vels Institute of Science, Technology \& Advanced Studies (VISTAS), Chennai-600117, India

${ }^{2}$ Centre for Advanced Research \& Development/Chemistry, Vels Institute of Science, Technology \& Advanced Studies (VISTAS), Chennai600117, India

*Corresponding author: E-mail: subraghu_0612@yahoo.co.in

Received: 2 January 2019;

Accepted: 2 February 2019;

Published online: 28 March 2019;

AJC-19349

\begin{abstract}
In this study, we report the hierarchically nanoporous activated carbons syntheses from most abundant bio-weed source of Ipomoea carnea stems by nickel foam template assisted with chemical and thermal activation method. The mixture of ferric chloride and diethyl ether of the activating agent and the impregnation ratios are investigated under constant temperature at $800{ }^{\circ} \mathrm{C}$ for $2 \mathrm{~h}$. The effective novel synthesized scheme and hierarchical nanoporous carbon structure with large specific surface areas of $1264.9 \mathrm{~m}^{2} \mathrm{~g}^{-1}$ and mean pore diameter of $2.1628 \mathrm{~nm}$. The electrochemical performance of prepared nanoporous structured carbon electrode is studied in non-aqueous $\left(\mathrm{TEABF}_{4}\right.$ ) electrolyte, which exhibits high specific capacitance of $257 \mathrm{Fg}^{-1}$ maximum energy density of $61.46 \mathrm{Wh} \mathrm{kg}^{-1}$ and power density of $13.32 \mathrm{~kW} \mathrm{~kg}^{-1}$ at $1 \mathrm{Ag}^{-1}$ with remarkable capacity retention of $90 \%$ for 10000 cycles. Therefore the present results show the suitability of synthesized material for use in energy storage applications. The representing promising application as a green route to synthesis advance nanoporous carbon materials from Ipomoea carnea biomass for high-capacity supercapaciors.
\end{abstract}

Keywords: Supercapacitor, High energy density, Biomass, Nanoporous carbon.

ᄂ - - - - - - - - - - - - - - - -

\section{INTRODUCTION}

The energy storage application and conversion systems are highly essential to meet ever growing demands. The high efficient, low cost effective, most abundant biomass resource materials and environmentally friendly are essential for activated carbon preparations. Nanoporous structured materials have involved excessive attention due to their many characteristics in these energy storage applications. These materials, typically nanoporous structured, exhibit faster charge transports and sometimes new electrochemical reactivity, which leads to their high energy density, high power density. A series of functional nanoporous structured materials have been fabricated with new synthetic schemes. Nanoporous materials technology and solid state electrochemistry have been attempted to be integrated in this study. New functional nanoporous materials have been required for electrochemical purpose.

Supercapacitors are regularly assisted as power source in electrochemical energy storage systems, due to their fast surface reaction mechanisms, including electrical double layer capacitors (EDLC) and pseudocapacitance [1,2]. The electrochemical capacitors (supercapacitors) are encouraging energy storage applications to replace the batteries applications, which demand effective charge/discharge, high energy, high power, long cycling life, safety, environment friendly and low cost [3]. Numerous carbon materials with high surface area and high porous carbon are regularly used as electrode materials of supercapacitors. In overall, carbon-based materials such as activated carbon [4], graphene [5], carbon nanotube [6], carbon nanofiber [7], templated porous carbon [8] and carbide derived carbon [9] are commonly used as electrode materials in electrochemical double layer capacitors. The biomass can be considered an unlimited source of activated carbon due to its multiplicity of sources [10]. The bio-carbon material are not conductive, but can be converted into highly conductive carbon-based nanoporous structured materials with suitable chemical and physical (thermal) management. For example, high-capacitance supercapacitors were systematized by using lignin as a biomass-derived source [11]

This is an open access journal, and articles are distributed under the terms of the Creative Commons Attribution-NonCommercial-ShareAlike 4.0 (CC BY-NC-SA 4.0) International License which allows readers to freely read, download, copy, distribute, print, search, or link to the full texts of its articles and to use them for any other lawful non-commercial purpose as long as the original source is duly acknowledged. 
Now a day, the researchers are investigating the biomass waste as a conceivable resource for synthesis of activated carbon [12]. Activated carbon prepared from various biomasses such as coal liquefaction residue [13], cow dung [14], tobacco stems [15], waste animal bones [16], fungi [17], torreya shell [18], human hair [19], pine nut shells [20], cotton stalk [21], coconut shell [22], waste coffee beans [23], olive pits [24], dead leaves [25] and Java Kapok shell [26], etc.

Extraordinary performance of supercapacitor electrodes have been found that apart from carbon precursor, high surface area and developed pore structure is dependent on the type of thermal activation and activation agents. The chemical activation with various pore forming reagents like $\mathrm{KOH}, \mathrm{NaOH}, \mathrm{ZnCl}_{2}$, $\mathrm{H}_{3} \mathrm{PO}_{3}, \mathrm{H}_{2} \mathrm{SO}_{4}$ usually active for the preparation of activated carbon [27-29]. Here we introduce, first time the novel template assisted with new activation agent (the mixture solution of ferric chloride with diethyl ether). Ferric chloride highly soluble in diethyl ether, so easily coated to nickel foam template at several time. The chemical-thermal activation was carried out with high-temperature at 600 to $1200{ }^{\circ} \mathrm{C}$ under inert atmosphere [30].

Ipomoea carnea is a bio-weed and commonly identified as bush morning glory is a weed found abundantly in India, Brazil, the USA, etc. [31]. Ipomoea carnea is content cellulose $55 \%$ and lignin $17 \%$. It grows abundantly on water bodies and marshy lands [32]. The weed causes neurological disorders in livestock on feeding [33], so, it cannot be used as a cattle feed. The wild growth and abundance of this plant make it a low-cost material. The stems are unsuitable to be used as firewood, because of low heating value and release of toxic gases during combustion [34].

The main objective of this study is controlled synthesis of uniform structured nano porous carbon by template assisted with new activation agent using Ipomoea carnea steams as raw material for the preparation of nanoporous carbon. The prepared uniform structured nano porous carbons are studied for high performance of supercapacitor applications.

\section{EXPERIMENTAL}

The precursor biomass resources of Ipomoea carnea stems were collected in Mukkur village, Thiruvannamalai district, Tamilnadu. India. Ferric chloride (Fisher Chemicals), diethyl ether (Sigma Aldrich), polytetrafluoroethylene $60 \%$ water dispersion (PTFE) (Sigma Aldrich), potassium hydroxide (SRL) and distilled water were purchased from Recon Scientific and Technology, Chennai. The non-aqueous electrolyte (supercapacitor grard) of tetraethylammonium tetrafluoroborate purchased from TOB in China. All the substances were use of analytical grade without purifying.

Synthesis of nanoporous activated carbon from Ipomoea carnea stems (IP-NPC): Ipomoea carnea stems was washed with pure distilled water at several times up to remove the impurities and dried at room temperature for $24 \mathrm{~h}$. After dried stems were pre-carbonized at $250^{\circ} \mathrm{C}$ for $1 \mathrm{~h}$ using muffle furnace in absence of air. The reaction system was naturally cooled down to room temperature in muffle furnace. Finally a carbon sample of Ipomoea carnea was obtained. Then, it was crushed into fine powder using mortar and pestle for further activation. After pre-carbonization, the activation process involves in two steps. The first involves the chemical impregnation of the ferric chloride and diethyl ether $\left(\mathrm{FeCl}_{3}: \mathrm{C}_{4} \mathrm{H}_{10} \mathrm{O}\right.$ :carbon) in addicted to the Ipomoea carnea carbon at weight percentage of 2.5:1:3 with continuous stirring for $12 \mathrm{~h}$, because of the iron(III) chloride highly soluble in diethyl ether. The reaction mixture coated on the nickel foam (NF) $(3 \mathrm{~cm} \times 3 \mathrm{~cm})$ surface for several times at 30-60 min time distance to take dry for layer of sample mixture. It was allowed to dry at room temperature. The second step involves the nickel foams with sample mixture were transferred in to ceramic boat and heated in a tubular furnace at $800{ }^{\circ} \mathrm{C}$ for $2 \mathrm{~h}$, under $\mathrm{N}_{2}$ atmosphere $(100$ $\mathrm{mL} / \mathrm{min}$ ). The resultant products were permitted to cool in tubular furnace and then soaked in concentrated hydrochloric acid with stirring until completely dissolved in nickel foam template. Subsequently, the products were washed with distilled water repeatedly until the neutral $\mathrm{pH}$ (about 6.5). Finally, the filtrated nano-structured activated carbons were dried at $250{ }^{\circ} \mathrm{C}$ for $1 \mathrm{~h}$ under nitrogen gas in a tubular furnace then crushed and sieved to sizes less than $0.15-0.074 \mathrm{~mm}$. The achieved Ipomoea carnea derived nanoporous carbons were labelled as IP-NPC.

Electrochemical characterization: The electrochemical properties of IP-NPC was examined using cyclic voltammetry $(\mathrm{CV})$, galvanostatic charge-discharge (CD) and electrochemical impedance spectroscopy (EIS) analysis using Biologics SP-300 potentiostat (France) and neware battery tester (China). The supercapacitor performances were tested in a two electrode symmetrical coin cell and swaglock cell.

The working electrode was fabricated by mixing IP-NPC, conductive carbon and Teflon binder (polytetrafluoroethylene $60 \%$ water dispersion) (PTFE) at a weight percentage of 85:10:5 with isopropanol. Finally, the mixture was rolled to thin film in thicknesses of $\sim 40$ and $200 \mu \mathrm{m}$ and then electrode film was cut into $10 \mathrm{~mm}$ diameter and dried in $100^{\circ} \mathrm{C}$ for $2 \mathrm{~h}$. The final average mass of the IP-NPC electrodes was $\sim 4-5 \mathrm{mg} / \mathrm{cm}^{2}$. The three electrodes cell (Sawgelock) using IP-NPC as a working electrode, $\mathrm{Ag} / \mathrm{AgCl}$ was a reference electrode and platinum was a counter electrode. The cyclic voltammetry and GCD investigates were carried out from the potential range in full cell for non-aqueous $0-2.7 \mathrm{~V}$ at various scan rate from $10-100 \mathrm{mV} \mathrm{s}^{-1}$.

The symmetric supercapacitor specific capacitance $\left(\mathrm{C}_{\mathrm{sp}}\right)$ was calculated from galvanostatic charge discharge results based on the total mass of electro active materials in two electrodes in following eqn. 1 :

$$
\mathrm{C}_{\mathrm{sp}}=\frac{2 \mathrm{I}}{\mathrm{dV} / \mathrm{dt}} \times \frac{1}{\mathrm{~m}}
$$

where, $\mathrm{m}$ is the mass of a single electrode $(\mathrm{g})$, I is the constant current (A) and $\mathrm{dV} / \mathrm{dt}$ was achieved by $\Delta \mathrm{V}$ is the potential change within the discharge time $\Delta \mathrm{t}$. The specific energy density, $E_{\text {cell }}\left(\mathrm{Wh} \mathrm{kg}^{-1}\right)$ and specific power density $\mathrm{P}_{\text {cell }}(\mathrm{kW}$ $\mathrm{kg}^{-1}$ ) for symmetric supercapacitor were calculated using the eqns. 2 and 3 :

$$
\begin{gathered}
\mathrm{E}=\frac{1}{2} \times \mathrm{C}_{\text {sp }} \times(\Delta \mathrm{V})^{2} \\
\mathrm{P}=\frac{\mathrm{E} \times 3600}{\Delta \mathrm{t}}
\end{gathered}
$$


where, $\mathrm{C}_{\mathrm{sp}}$ is the specific capacitance of a symmetric supercapacitor, $\Delta \mathrm{V}$ is the voltage range and $\Delta \mathrm{t}$ is the discharge time.

\section{RESULTS AND DISCUSSION}

The morphological appearances of the nanoporous carbons prepared from Ipomoea carnea (IP-NPC) was studied by the field emission scanning electron microscope (FESEM), shown in Fig. 1(a\&b). The chemical activation $\left(\mathrm{FeCl}_{3}\right.$-diethyl ether mixture) experiments carried out at $800{ }^{\circ} \mathrm{C}$ and the results shows the uniform pores on the carbon surface and arranged irregular shaped needle like high rough surfaces with nanoporous (Fig. 1(b)). The resulting formation of rough surface with nanoporous structure and nanoneedles on the surface could be enhance the conductivity, ionic movement of the electrolyte which might be helpful for high power density supercapactior applications.

The microstructure of IP-NPC was studied by HRTEM as shown in Fig. 1(c) at higher magnification. The small size of microporous, nanoporous and carbon particles accumulates could be realized in HRTEM images. The resulting IP-NCP nanoporous surface could enhanced the electrolyte penetration to access the electrochemical energy storage of the supercapacitor performance.

The XRD patterns of prepared IC-NAP shown in Fig. 1(d). The observed pattern exhibited two broad peaks at $2 \theta$, in $24.50^{\circ}$ and $43.85^{\circ}$ peaks correspond to (002) and (100) reflections respectively. The chemical activation with high-temperature pyrolysis was a control for the development of controlled synthesis of amorphous carbon with nano porous structure [35]. The prepared carbon interlayer spacing values $(0.363 \mathrm{~nm})$, average crystal size (73 nm), layer thickness (LC) $(3.912 \mathrm{~nm})$ and layer-plane length (La) (1.934 nm) value of prepared nanoporous carbon (IP-NPC) were observed and results shown in Table-1.

Raman spectra for synthesized IP-NPC have been shown in Fig. 2(a). The Raman spectra mainly studied in structural investigation of nano carbon material's and, determining defects and ordered/disordered structures [36]. Three sharp bands were presented, in the D band (disorder band) at $1350-1340 \mathrm{~cm}^{-1}$ can be associated with the presence of structural defects, $\mathrm{G}$ band) at $1590-1580 \mathrm{~cm}^{-1}$. Its intensity is significantly influenced by the number of graphitic layers and 2D band (a two-dimensional
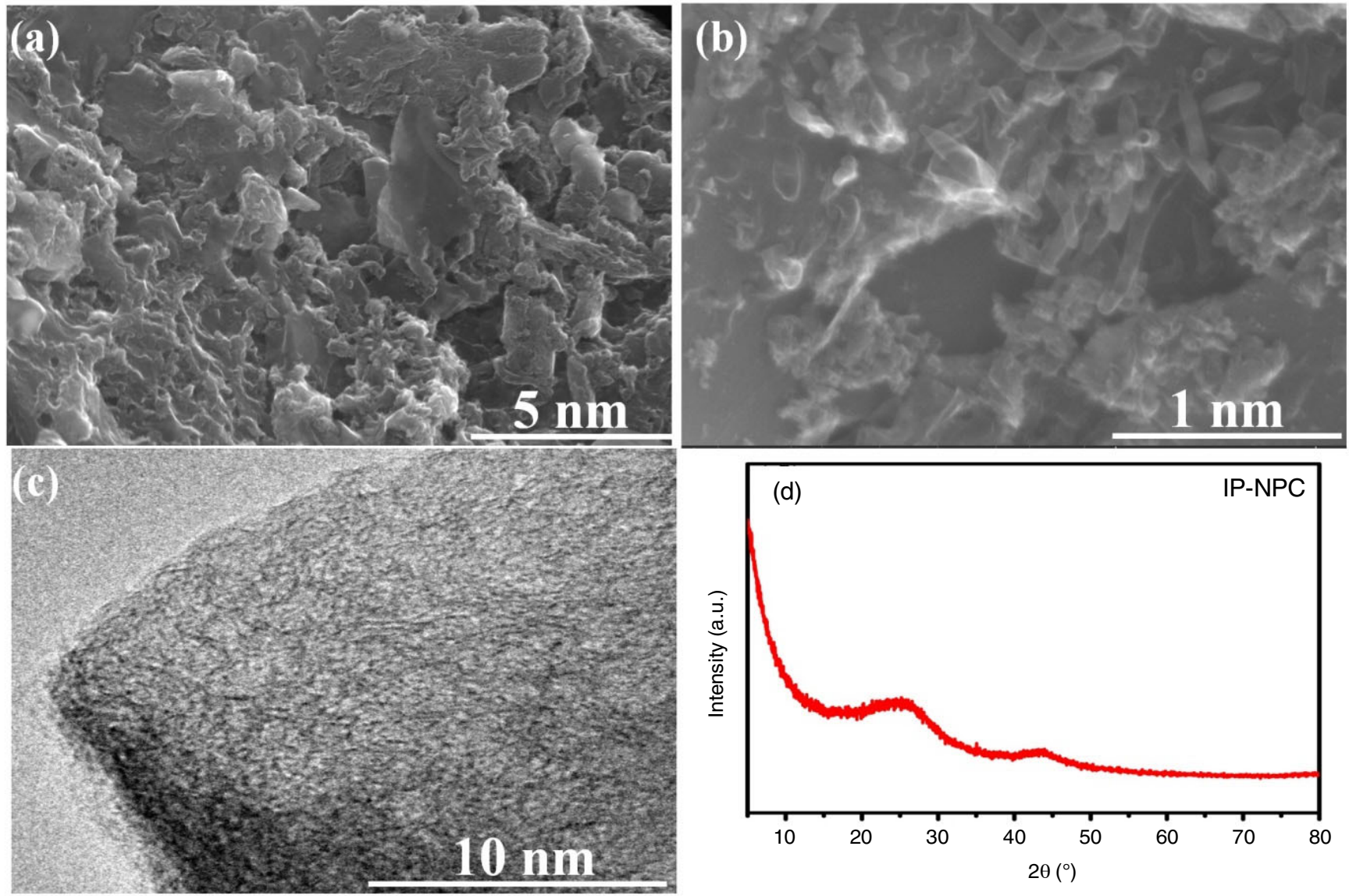

Fig. 1. (a \& b) FE-SEM images of active carbon materials (IP-NPC) at different magnifications, (c) HR-TEM images of IP-NPC with show the aggregation of few nanometer-size carbon particles, (d) XRD pattern of IP-NPC

\begin{tabular}{cccccccc}
\multicolumn{1}{c}{ TABLE-1 } \\
XRD DATA OF IP-NPC \\
\hline Samples & FWHW & 002 peak & $\begin{array}{c}\mathrm{d}_{002} \text { spacing } \\
(\mathrm{nm})\end{array}$ & $\begin{array}{c}\text { Crystalline } \\
\text { width }\left(\mathrm{L}_{\mathrm{a}}\right)(\mathrm{nm})\end{array}$ & $\begin{array}{c}\text { Crystalline } \\
\text { height }\left(\mathrm{L}_{\mathrm{c}}\right)(\mathrm{nm})\end{array}$ & $\begin{array}{c}\text { Crystalline size } \\
(\mathrm{nm})\end{array}$ & $\begin{array}{c}\text { Graphitization } \\
\text { degree }(\mathrm{g})(\%)\end{array}$ \\
\hline IP-NPC & 12.61 & 24.50 & 0.363 & 3.9123 & 1.9349 & 0.73 & 2.37 \\
\hline
\end{tabular}


band) at about $2900-2684 \mathrm{~cm}^{-1}$. The one more band appearance at $2450 \mathrm{~cm}^{-1}$ (D+D") [37]. The G band is characteristic of all $s p^{2}$-based materials [38], while the intensity ratio (IG/ID) may be associated with the number of defects present within the graphene sheets [39]. The Raman measurements of IP-NPC show as a D band at $1331 \mathrm{~cm}^{-1}, \mathrm{D}$ band at $1597 \mathrm{~cm}^{-1}, \mathrm{D}+\mathrm{D}$ " band at $2437.5 \mathrm{~cm}^{-1}$ and 2D band at $2938 \mathrm{~cm}^{-1}$. Table-2 shown that the IP-NPC, integrated intensity ratios (ID/IG) and I2D/IG were calculated and presented.

The FTIR studies determine the different functional groups on the surfaces of amorphous carbon as Fig. 2(b). The resulting in IP-NPC as found a peaks at 3783 and $3434 \mathrm{~cm}^{-1}$ are representative in the presence of the $\mathrm{OH}$ functional group. It was mostly attributed to chemisorbed water molecules and $\mathrm{OH}$ groups on the carbon surface. The FTIR spectrum of IP-NPC sample demonstration numerous peaks at 2927, 1572, 1111 and 588 $\mathrm{cm}^{-1}$ due to several oxygen holding functional groups like $-\mathrm{CH}_{2}, \mathrm{C}=\mathrm{O}$ and $\mathrm{C}-\mathrm{OH}$, respectively [40].

The adsorption/desorption isotherms of prepared IP-NPC was shown in Fig. 2(c). The typical I-type adsorption isotherm (Langmuir isotherm) was obtained and pores are typically microporous with the exposed surface residing almost exclusively inside the microspores, which once filled with adsorbate, leave little or no external surface for further adsorption. The pores arrangements are explained by physical properties of prepared nanoporous activated carbons (IP-NPC) including BET surface area (SBET), total pore volume (VT) and average pore diameter (Dp) are given in Table-2. The Brunauer-Emmett-Teller (BET) surface area and the total pore volume (VT) of the IP-NPC sample is $1264 \mathrm{~m}^{2} \mathrm{~g}^{-1}$ and $0.63 \mathrm{~cm}^{3} \mathrm{~g}^{-1}$, respectively.

Fig. 2(c) shows the pore size distributions of prepared activated carbon sample (IP-NPC). The adsorbent pores were
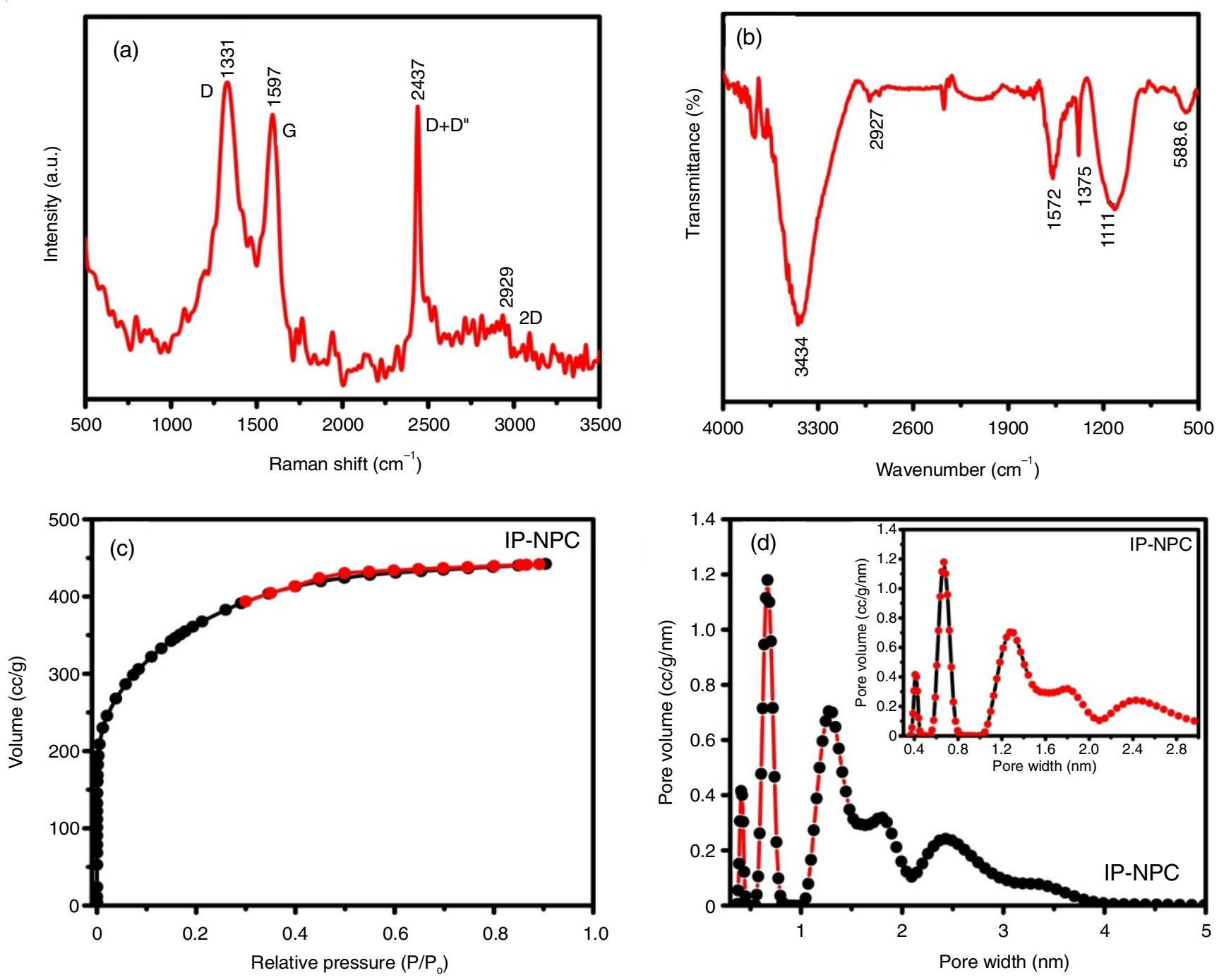

Fig. 2. (a) Raman spectra, (b) FT-IR spectra of prepared IP-NPC materials, (c) Nitrogen adsorption-desorption isotherms, (d) Pore-size distribution of IP-NPC

TABLE-2

RAMAN AND BET CALCULATIONS FOR IP-NPC

\begin{tabular}{cccccc}
\hline Samples & ID/IG & I2D/IG & $\begin{array}{c}\text { BET surface area } \\
(\text { SBET })\left(\mathrm{m}^{2} \mathrm{~g}^{-1}\right)\end{array}$ & $\begin{array}{c}\text { Pore volumes } \\
(\mathrm{VP})\left(\mathrm{cm}^{3} \mathrm{~g}^{-1}\right)\end{array}$ & $\begin{array}{c}\text { Mean pore diameter } \\
(\mathrm{DP})(\mathrm{nm})\end{array}$ \\
\hline IP-NPC & 1.94 & 0.96 & 1264 & 0.684 & 2.162 \\
\hline
\end{tabular}


categorized into three main groups, microspores at diameter $<2 \mathrm{~nm}$, mesoporous at 2-50 $\mathrm{nm}$ and macropores at $>50 \mathrm{~nm}$. The results indicates, IP-NPC contain highly micropores with small amount of mesopores.

The electrochemical performance of the prepared activated carbon (IP-NPC) was studied by using a two-electrode system in organic $\left(\mathrm{TEABF}_{4}\right)$ electrolyte, that shown in Fig. 3. The cyclic voltammetry (CV) plot of symmetric IP-NPC active material at different voltages were shown in Fig. 3(a). The highest specific capacitance of active material (IP-NPC) was found $143 \mathrm{Fg}^{-1}$ at $20 \mathrm{mV} \mathrm{s}^{-1}$ from the $\mathrm{CV}$ curves. Also the galvanostatic charge discharge specific capacitance of two electrode system, exhibited a maximum value of $139 \mathrm{Fg}^{-1}$ at $1 \mathrm{Ag}^{-1}$ current density in organic electrolyte. Fig. 3(b) explains that the cycling stability was studied at $1 \mathrm{Ag}^{-1}$ current density, representative that more than $90 \%$ of retention of the initial capacitance was observed after 10000 charge-discharge cycles. The GCD curve was symmetrical, low voltage drop (IR), almost linear stability and indicating a good capacity performance, more than $99 \%$ columbic efficiency and good conductivity. The Impedances (Nyquist) plots of active material (IP-NPC) before cycle and after 10000 cycles were compared and shown in Fig. 4(c). The outline of these two Nyquist plots were the similar, but analysis these impedances, the internal resistance of before and after 10000 cycles was increased.

\section{Conclusion}

Here we report the nanoporous activated carbon was derived from the bio-weed of Ipomoea carnea stems using the chemical activation with $\mathrm{FeCl}_{3}$ and diethyl ether mixture. The nickel template method using impregnate-activation procedure followed by a $\mathrm{HCl}$ etching resulted in a high surface area and increase the micro porous structures with effect of activation temperature $\left(800^{\circ} \mathrm{C}\right.$ for $2 \mathrm{~h}$ ). The resulted of synthesis carbon electrodes show superior capacitive performance, outstanding cycle stability and specific capacitance. In a two electrode system, it was establish that highest specific capacitances of $139 \mathrm{~F} \mathrm{~g} \mathrm{~g}^{-1}$ in the organic electrolyte $\left(\mathrm{TEABF}_{4}\right)$ at the current density of $1 \mathrm{Ag}^{-1}$. The combined nanoporous and microporous structure leads to a noble rate ability of more than $90 \%$ capacitance retention at current density up to $1 \mathrm{Ag}^{-1}$ in the nonaqueous electrolyte. The novel synthesis nanoporous carbon material can store/release extreme the energy density of 61.46 Wh kg-1 and power density of $13.32 \mathrm{~kW} \mathrm{~kg}^{-1}$ in the $\mathrm{TEABF}_{4}$ electrolyte. The experimental results confirmation the nanoporous structured carbon electrodes is an outstanding electro-
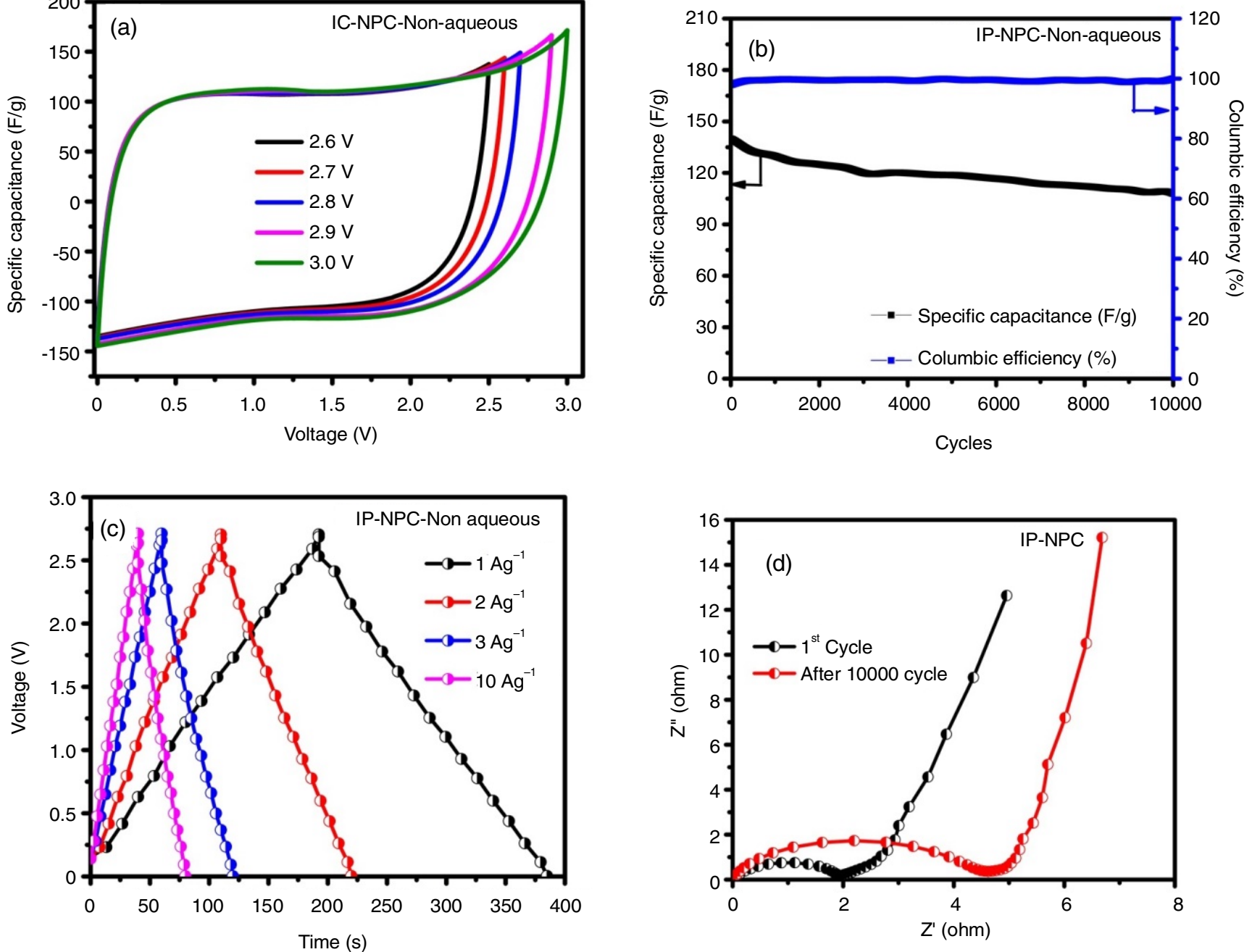

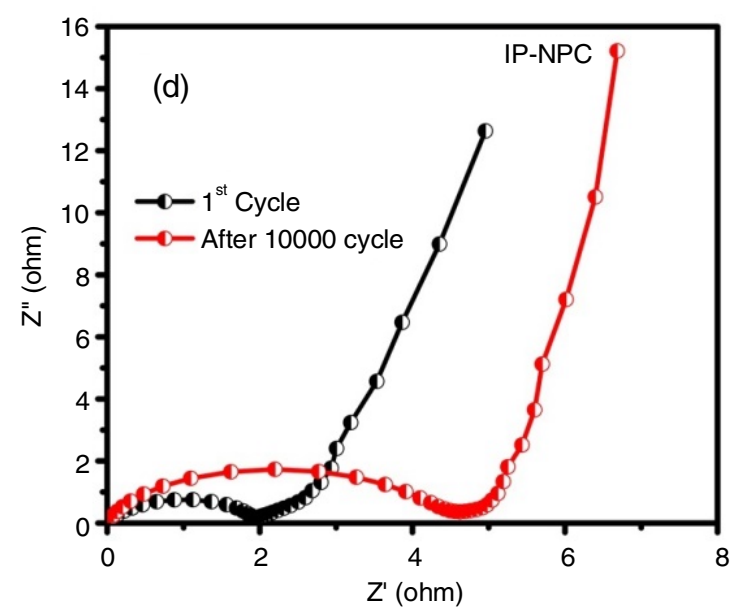

Fig. 3. (a) Electrochemical performance of a IP-NPC in Non-aqueous electrolyte at different operating volt in $20 \mathrm{mV} \mathrm{s}^{-1}$, (b) Specific capacitance retention and efficiency as a function of cycle number for 10000 cycles, (c) GCD curves of the symmetric two electrode system at different current densities, (d) Nyquist plot of IP-NPC with organic electrolyte 
chemical performance, suitability of cost-effective, high abundance. Hence, this material supposed to be a useful for energy storage devices like supercapacitors and batteries.

\section{ACKNOWLEDGEMENTS}

The authors grateful thanks the Science \& Engineering Research Board, Department of Science and Technology (DSTSERB), Government of India. (DST/ECR/SERB/000815/ 2017). The first author (K. Thileep Kumar) thanks to DST for Grant Junior Research fellow (JRF). We thank to Central Instrumentation Lab, VISTAS, Chennai.

\section{CONFLICT OF INTEREST}

The authors declare that there is no conflict of interests regarding the publication of this article.

\section{REFERENCES}

1. M.F. El-Kady, Y. Shao and R.B. Kaner, Nature Rev. Mater, 1, 16033 (2016);

https://doi.org/10.1038/natrevmats.2016.33.

2. M. Salanne, B. Rotenberg, K. Naoi, K. Kaneko, P.L. Taberna, C.P. Grey, B. Dunn and P. Simon, Nature Energy, 1, 16070 (2016); https://doi.org/10.1038/nenergy.2016.70.

3. Y. Li, Z. Li and P.K. Shen, Adv. Mater, 25, 2474 (2013); https://doi.org/10.1002/adma.201205332.

4. M. Wahid, D. Puthusseri, D. Phase and S. Ogale, Energy Fuels, 28, 4233 (2014); https://doi.org/10.1021/ef500342d.

5. L.L. Zhang, R. Zhou and X.S. Zhao, J. Mater. Chem., 20, 5983 (2010); https://doi.org/10.1039/c000417k.

6. G. Lota, K. Fic and E. Frackowiak, Energy Environ. Sci., 4, 1592 (2011); https://doi.org/10.1039/c0ee00470g

7. H. Wang, W. Wang, H. Wang, X. Jin, H. Niu, H. Wang, H. Zhou and T. Lin, ACS Appl. Energy Mater., 1, 431 (2018);

https://doi.org/10.1021/acsaem.7b00083.

8. M. Lazzari, F. Soavi and M. Mastragostino, Fuel Cells, 10, 840 (2010); https://doi.org/10.1002/fuce.200900198.

9. J. Chmiola, C. Largeot, P.L. Taberna, P. Simon and Y. Gogotsi, Science, 328, 480 (2010);

https://doi.org/10.1126/science.1184126.

10. S. Zheng, H. Xue and H. Pang, Coord. Chem. Rev., 373, 2 (2018); https://doi.org/10.1016/j.ccr.2017.07.002.

11. S. Zheng, X. Li, B. Yan, Q. Hu, Y. Xu, X. Xiao, H. Xue and H. Pang, Adv. Energy Mater., 7, 1602733 (2017); https://doi.org/10.1002/aenm.201602733.

12. R.A. Voloshin, M.V. Rodionova, S.K. Zharmukhamedov, T.N. Veziroglu and S.I. Allakhverdiev, Int. J. Hydrogen Energy, 41, 17257 (2016); https://doi.org/10.1016/j.ijhydene.2016.07.084.

13. G. Huang, W. Kang, B. Xing, L. Chen and C. Zhang, Fuel Process. Technol., 142, 1 (2016); https://doi.org/10.1016/j.fuproc.2015.09.025.

14. K.K. Gupta, K.R. Aneja and D. Rana, Bioresour. Bioprocess., 3, 28 (2016); https://doi.org/10.1186/s40643-016-0105-9.

15. M. Gnerlich, H. Ben-Yoav, J.N. Culver, D.R. Ketchum and R. Ghodssi, J. Power Sources, 293, 649 (2015); https://doi.org/10.1016/j.jpowsour.2015.05.053

16. U. Iriarte-Velasco, I. Sierra, L. Zudaire and J.L. Ayastuy, J. Mater. Sci., 50, 7568 (2015); https://doi.org/10.1007/s10853-015-9312-6

17. J. Wang, I. Senkovska, S. Kaskel and Q. Liu, Carbon, 75, 372 (2014); https://doi.org/10.1016/j.carbon.2014.04.016.
18. H. Xuan, G. Lin, F. Wang, J. Liu, X. Dong and F. Xi, J. Solid State Electrochem., 21, 2241 (2017); https://doi.org/10.1007/s10008-017-3562-y.

19. M.J. Ahmed, M.A. Islam, M. Asif and B.H. Hameed, Bioresour. Technol., 243, 778 (2017); https://doi.org/10.1016/j.biortech.2017.06.174

20. D. Chen, X. Chen, J. Sun, Z. Zheng and K. Fu, Bioresour. Technol., 216, 629 (2016); https://doi.org/10.1016/j.biortech.2016.05.107.

21. M. Chen, X. Kang, T. Wumaier, J. Dou, B. Gao, Y. Han, G. Xu, Z. Liu and L. Zhang, J. Solid State Electrochem., 17, 1005 (2013); https://doi.org/10.1007/s10008-012-1946-6.

22. A. Sarswat and D. Mohan, RSC Adv., 6, 85390 (2016); https://doi.org/10.1039/C6RA19756F

23. Y.S. Yun, M.H. Park, S.J. Hong, M.E. Lee, Y.W. Park and H.J. Jin, ACS Appl. Mater. Interfaces, 7, 3684 (2015); https://doi.org/10.1021/am5081919.

24. J. Ajuria, E. Redondo, M. Arnaiz, R. Mysyk, T. Rojo and E. Goikolea, J. Power Sources, 359, 17 (2017); https://doi.org/10.1016/j.jpowsour.2017.04.107.

25. R. Madhu, K.V. Sankar, S.M. Chen and R.K. Selvan, RSC Adv., 4, 1225 (2014); https://doi.org/10.1039/C3RA45089A.

26. K.T. Kumar, G.S. Sundari, E.S. Kumar, S. Raghu, A. Ashwini, M. Ramya, P. Varsha, R. Kalaivani, M. Shanmugaraj Andikkadu, V. Kumaran, R. Gnanamuthu, S.Z. Karazhanov and S. Raghu, Mater. Lett., 218, 181 (2018); https://doi.org/10.1016/j.matlet.2018.02.017.

27. B. Xu, F. Wu, R. Chen, G. Cao, S. Chen and Y. Yang, J. Power Sources, 195, 2118 (2010); https://doi.org/10.1016/j.jpowsour.2009.09.077.

28. T.E. Rufford, D. Hulicova-Jurcakova, K. Khosla, Z. Zhu and G.Q. Lu, J. Power Sources, 195, 912 (2010); https://doi.org/10.1016/j.jpowsour.2009.08.048.

29. D. Prahas, Y. Kartika, N. Indraswati and S. Ismadji, Chem. Eng. J., 140, 32 (2008); https://doi.org/10.1016/j.cej.2007.08.032

30. A. Ahmadpour and D.D. Do, Carbon, 34, 471 (1996); https://doi.org/10.1016/0008-6223(95)00204-9.

31. A.K. Patel, V.K. Singh, R.P. Yadav, A.J. Moir and M.V. Jagannadham, Phytochemistry, 70, 1210 (2009); https://doi.org/10.1016/j.phytochem.2009.07.005.

32. P. Sankarganesh, R. Sanjeevi, S. Gajalakshmi, E. Ramasamy and S. Abbasi, Bioresour. Technol., 99, 812 (2008); https://doi.org/10.1016/j.biortech.2007.01.024

33. A. Schwarz, S.L. Gorniak, M.M. Bernardi, M.L. Dagli and H.S. Spinosa, Neurotoxicol. Teratol., 25, 615 (2003); https://doi.org/10.1016/S0892-0362(03)00078-3.

34. D. Konwer, R. Kataki and M. Saikia, Energy Sources Part A, 29, 817 (2007); https://doi.org/10.1080/00908310500281189.

35. T. Chen, Y. Tang, Y. Qiao, Z. Liu, W. Guo, J. Song, S. Mu, S. Yu, Y. Zhao and F. Gao, Sci. Rep., 6, 23289 (2016); https://doi.org/10.1038/srep23289.

36. P. Hojati-Talemi and G.P. Simon, Carbon, 48, 3993 (2010); https://doi.org/10.1016/j.carbon.2010.06.062.

37. P. May, M. Lazzeri, P. Venezuela, F. Herziger, G. Callsen, J.S. Reparaz, A. Hoffmann, F. Mauri and J. Maultzsch, Phys. Rev. B, 87, 075402 (2013); https://doi.org/10.1103/PhysRevB.87.075402.

38. M.S. Dresselhaus, A. Jorio, M. Hofmann, G. Dresselhaus and R. Saito, Nano Lett., 10, 751 (2010); https://doi.org/10.1021/n1904286r.;

39. M.M. Lucchese, F. Stavale, E.H.M. Ferreira, C. Vilani, M.V.O. Moutinho, R.B. Capaz, C.A. Achete and A. Jorio, Carbon, 48, 1592 (2010); https://doi.org/10.1016/j.carbon.2009.12.057.

40. H. Zhang, X. Yu, D. Guo, B. Qu, M. Zhang, Q. Li and T. Wang, ACS Appl. Mater. Interfaces, 5, 7335 (2013); https://doi.org/10.1021/am401680m 